See discussions, stats, and author profiles for this publication at: https://www.researchgate.net/publication/323094793

\title{
Reversible, Repeatable and Low Phase Transition Behaviour of Spin Coated Nanostructured Vanadium Oxide Thin Films with Superior Mechanical Properties
}

Article in Ceramics International · February 2018

DOI: 10.1016/j.ceramint.2018.02.085

10 authors, including:

Arjun Dey

Government of India

186 PUBLICATIONS 1,012 CITATIONS

SEE PROFILE

\section{Debajyoti Palai}

Indian Institute of Technology Kharagpur

8 PUBLICATIONS 10 CITATIONS

SEE PROFILE

Some of the authors of this publication are also working on these related projects:

Project TRANSPARENT CONDUCTORS View project

Project Thin film coatings View project 


\title{
Reversible, repeatable and low phase transition behaviour of spin coated nanostructured vanadium oxide thin films with superior mechanical properties
}

\author{
Dipta Mukherjee ${ }^{\mathrm{a}}$, Arjun Dey ${ }^{\mathrm{b}, *}$, A. Carmel Mary Esther ${ }^{\mathrm{b}}$, Debajyoti Palai ${ }^{\mathrm{c}}$, N. Sridhara ${ }^{\mathrm{b}}$, \\ Parthasarathi Bera ${ }^{\mathrm{d}}$, Manjima Bhattacharya ${ }^{\mathrm{a}}$, A. Rajendra ${ }^{\mathrm{b}}$, Anand Kumar Sharma ${ }^{\mathrm{b}}$, \\ Anoop Kumar Mukhopadhyay ${ }^{\mathrm{a}, *}$
}

a Advanced Mechanical and Materials Characterization Division, CSIR-Central Glass and Ceramic Research Institute, Kolkata 700032, India

${ }^{\mathrm{b}}$ ISRO Satellite Centre, Bangalore 560017, India

${ }^{\mathrm{c}}$ Department of Metallurgy and Materials Engineering, Indian Institute of Technology, Kharagpur 721302, India

${ }^{\mathrm{d}}$ Surface Engineering Division, CSIR-National Aerospace Laboratories, Bangalore 560017, India

\section{A R T I C L E I N F O}

\section{Keywords:}

Vanadium oxide thin film

XPS

Reversible phase transition

DSC

Optical properties

Nanoindentation

\begin{abstract}
A B S T R A C T
Smooth, uniform and crystalline vanadium oxide thin films were deposited on quartz by spin coating technique with four different rpm i.e., 1000, 2000, 3000 and 4000 and subsequently post annealed at 350,450 and $550{ }^{\circ} \mathrm{C}$ in vacuum. Transmission electron microscopy (TEM), Field emission scanning electron microscopy (FESEM) and $\mathrm{X}$-ray diffraction (XRD) techniques were utilized for microstructural characterizations and phase analysis, respectively, for vanadium oxide powder and deposited film. Nanorods were observed to be grown after vacuum annealing. X-ray photoelectron spectroscopy (XPS) technique was utilized to study the elemental oxidation state of deposited vanadium oxide films. Thermo-optical and electrical properties such as solar transmittance $\left(\tau_{\mathrm{s}}\right)$, reflectance $\left(\rho_{s}\right)$, absorptance $\left(\alpha_{s}\right)$, infrared (IR) emittance $\left(\varepsilon_{\text {ir }}\right)$ and sheet resistance $\left(R_{s}\right)$ of different thin films were evaluated. Based on the optical characteristics the optimized condition of the film processing was identified to be spin coated at $3000 \mathrm{rpm}$. Subsequently, the nanoindentation technique was utilized to measure hardness and Young's modulus of the optimized film. The measured nanomechanical properties were found to be superior to those reported for sputtered vanadium oxide films. Finally, temperature dependent phase transition characteristics of optimized vanadium oxide films were studied by differential scanning calorimetry (DSC) technique. Reversible and repeatable phase transition was found to occur in the range of $44-48^{\circ} \mathrm{C}$ which was significantly lower than the phase transition temperature (i.e., $68^{\circ} \mathrm{C}$ ) of bulk $\mathrm{VO}_{2}$.
\end{abstract}

\section{Introduction}

Vanadium oxides are multivalent phase transition material. The valence states of its oxide include $2+, 3+, 4+, 5+$ etc. and several intermediate oxide states. Each different variety possesses different phase transition temperatures. Currently, the research and development is mainly focussed on $\mathrm{VO}_{2}$ and $\mathrm{V}_{2} \mathrm{O}_{5}$ based thin films since they exhibit reversible phase transition in the positive temperature regime unlike other contemporary vanadium oxide analogues which exhibit phase transitions at sub-zero level of temperatures.

Actually, upon heating of $\mathrm{VO}_{2}$ thin films beyond its transition temperature, the monoclinic structure ( $\mathrm{M} 1$ phase, $\mathrm{P} 21 / \mathrm{c}$,) is transformed to the tetragonal structure (R phase, space group $P 42 / \mathrm{mnm}$ ) [1] and a corresponding semiconductor to metal (SMT) transition is observed that is also reversible in nature. This phase transition has been extensively investigated for the very first time by Mott [2]. According to Mott [2], the lattice distortion caused by the phase transition enhances the energy gap between the occupied and empty states. But since the entropy of the electrons present in the occupied state is increased with increase in temperature, the energy gap becomes diminished and this provides metallic behaviour to the material. The recent reports successfully observed the reversible phase transition of $\mathrm{V}_{2} \mathrm{O}_{5}$ thin films [3-5] although there were some early debates regarding it. Thus, it is now well established that besides $\mathrm{VO}_{2}$ the reversible phase transition is also exhibited by $\mathrm{V}_{2} \mathrm{O}_{5}$.

The reversible phase transition in vanadium oxide system triggers significant changes in thermo-optical and electrical properties. Since, unlike other vanadium oxide analogues $\mathrm{VO}_{2}$ has its phase transition

\footnotetext{
* Corresponding authors.

E-mail addresses: arjundey@isac.gov.in, arjun_dey@rediffmail.com (A. Dey), anoopmukherjee@cgcri.res.in, mukhopadhyay.anoop@gmail.com (A.K. Mukhopadhyay).
} 
temperature much closer to room temperature it has potential applications in the fields of storage devices [6], switching devices [7], smart windows [8], field effect transistors [9] and antireflective smart coatings [10]. Further, it has been reported recently [10-12] that $\mathrm{VO}_{2}$ based thin films could offer a smart, efficient and radiative thermal control characteristic for spacecraft application. Since for developing micro/ nano satellites, the reduction of mass and an efficient mode of thermal control is the foremost challenge; utilisation of $\mathrm{VO}_{2}$ based smart coatings on outer bodies of spacecraft provides the way-out. Present work is also aiming towards the development of a material for smart radiative thermal control application in satellites.

For the fabrication of $\mathrm{VO}_{2}$ thin films; several methods have been adopted e.g., magnetron sputtering [13], pulsed laser deposition [14], chemical vapour deposition [15] and sol-gel $[16,17]$ etc. Among all the deposition techniques for development of vanadium oxide thin films, sol-gel spin/dip coating is most economic and facile mode of synthesis. In fact, sol-gel based coating technique can be adopted for scale up purpose especially for spacecraft application where big panels would be coated.

In general, the transition temperature for pure $\mathrm{VO}_{2}$ is around $65-68^{\circ} \mathrm{C}[8,12,13,18]$ while the transition temperature of $\mathrm{V}_{2} \mathrm{O}_{5}$ is reported to be in the wide range of $\sim 127-343^{\circ} \mathrm{C}$ [3-5] which is still a debatable issue. The aforesaid temperature limit is not suitable for spacecraft and other opto-electronic applications. Thus, several efforts have been made further to achieve the phase transition in lower temperature region (near/just above the room temperature) e.g., in the range of $54-65^{\circ} \mathrm{C}[18], 48{ }^{\circ} \mathrm{C}[19], 45-49^{\circ} \mathrm{C}[11], 32^{\circ} \mathrm{C}[20], 31-57^{\circ} \mathrm{C}$ [21], $30^{\circ} \mathrm{C}[22]$, and $29^{\circ} \mathrm{C}[23,24]$ for pure $\mathrm{VO}_{2}$ thin films. To tune the transition temperature of $\mathrm{VO}_{2}$ near room temperature, the attempts have been made by doping of various elements including transition metals such as Sn [25], W [26], N [27], Mo [10,28], Ti [29], Mg [30] etc. into the vanadium oxide matrix, by adding some second phases i.e., by making composites [31,32] followed subsequently by post annealing in vacuum $[10,33]$ or under reducing environments e.g., $\mathrm{H}_{2}, \mathrm{~N}_{2} / \mathrm{Ar}$ [34].

However, systematic and comprehensive studies with variations in vacuum annealing temperatures and its effect on film as well as functional properties have remained largely unexplored. Therefore, in the present work, attempt has been made to reduce the transition temperature of vanadium oxide without any doping or any incorporation of second phase. Post annealing in vacuum was adopted to obtain $\mathrm{VO}_{2}$ from the $\mathrm{V}_{2} \mathrm{O}_{5}$ rich film. Here, vanadium oxide thin films were grown on quartz substrate by sol-gel spin coating route. Thin films were deposited at typical rpm of 1000, 2000, 3000, and 4000. The microstructural characterizations of powder and films were carried out by transmissionelectron microscopy (TEM) and field emission scanning electron microscopy (FESEM). Deposited thin films were subsequently annealed at three different temperatures e.g., 350,450 and $550{ }^{\circ} \mathrm{C}$ under high vacuum $\left(1.5 \times 10^{-5} \mathrm{mbar}\right)$. Phase analysis of the thin films was characterised by X-ray diffraction (XRD). The thermo-optical properties viz., solar transmittance, reflectance, absorptance, IR emittance and sheet resistance were also evaluated as a function of vacuum annealing temperatures. For the film developed under optimized condition, the film thickness and nanomechanical properties of thin film were carried out by non-contact mode surface profilometric analysis and nanoindentation techniques, respectively. Finally, the phase transition behaviour and elemental oxidation state of the thin films was also investigated by the differential scanning calorimetry (DSC) and X-ray photo-electron spectroscopy (XPS) techniques, respectively.

\section{Materials and methods}

\subsection{Synthesis of powder}

The vanadium oxide powder was synthesized from aqueous solution of ammonium metavanadate $\left(\mathrm{NH}_{4} \mathrm{VO}_{3}, 99.0 \%\right.$, ACS reagent, Sigma

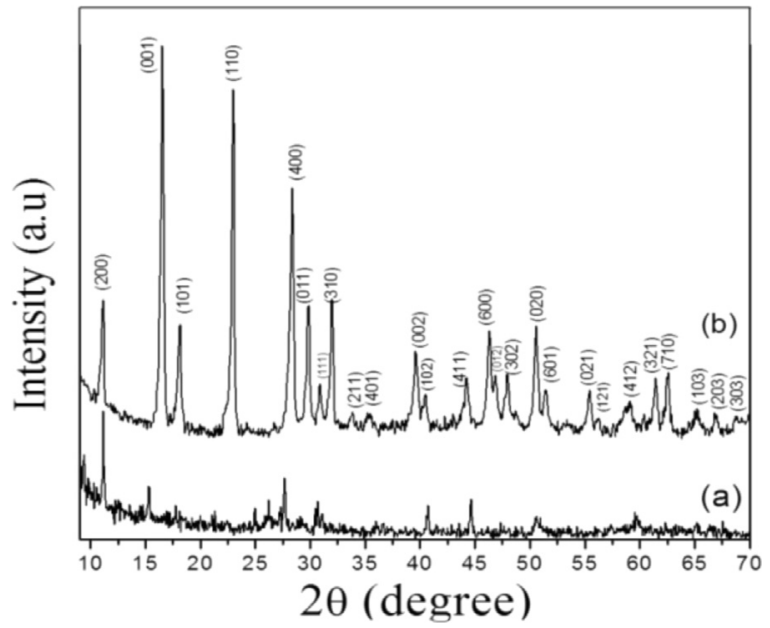

Fig. 1. XRD patterns of vanadium oxide powders: (a) as-precipitated and (b) heat-treated at $450{ }^{\circ} \mathrm{C}$ in air.

Aldrich) by well-known acid hydrolysis technique using hydrochloric acid $(37 \% \mathrm{HCl}$, Thermo Fisher Scientific India Pvt. Ltd., Mumbai, India). All procured chemicals were used in the as-received condition without any further purification. Double distilled water was used for the preparations of both the aqueous solution and the dilute $\mathrm{HCl}$ (e.g., $\sim 0.3 \mathrm{M}$ ). In a typical synthesis procedure, $5 \mathrm{~g}$. of $\mathrm{NH}_{4} \mathrm{VO}_{3}$ was added to $150 \mathrm{ml}$ of distilled water taken in a glass beaker. The solution was then vigorously stirred at $90{ }^{\circ} \mathrm{C}$ for $30 \mathrm{~min}$. After some time the solution colour turned yellow and $5 \mathrm{ml}$. of $\mathrm{HCl}(0.3 \mathrm{M})$ was added to it in a dropwise manner. Upon addition of $\mathrm{HCl}$ the solution immediately changed colour from canary yellow to reddish brown. The reddish brown solution was stirred further for about $35-45 \mathrm{~min}$ and deep brown colour vanadium oxide powder was then observed. The $\mathrm{pH}$ of the resultant solution containing the powder was measured to be around 2-2.5. The brown-red powder was then collected by filtration. It was further washed several times with distilled water to remove excess acid, if any. This step was followed by air drying at $60^{\circ} \mathrm{C}$. Finally, the as synthesized powder was further subjected to one hour heat treatment at $450{ }^{\circ} \mathrm{C}$ in air.

\subsection{Synthesis of gel and deposition of thin films}

In a typical procedure of gel synthesis; about $0.6547 \mathrm{~g}$ of the heat treated powder was dissolved in $40 \mathrm{ml}$ of $15 \% \mathrm{H}_{2} \mathrm{O}_{2}$ (Merck Specialities Pvt. Ltd., Mumbai, India). Here, $\mathrm{H}_{2} \mathrm{O}_{2}$ was expected to act also as a reducing agent which could be subsequently conducive to obtain $\mathrm{VO}_{2}$ while casting film. The solution mixture was then placed in a water bath (e.g., $\sim 90^{\circ} \mathrm{C}$ ) with vigorous stirring at $700 \mathrm{rpm}$ to prepare the sol. Upon heating the sol for about $20 \mathrm{~min}$ at $\sim 90^{\circ} \mathrm{C}$ in a water bath with constant stirring, the sol transformed to a deep brown coloured stable viscous gel. The viscosity of the gel depends on the heating time and temperature of the water bath. The $\mathrm{pH}$ of the gel was found to be $\sim 1.5$. Subsequently, the synthesized gel was utilized for preparation of the thin films.

Quartz substrates (Astro Optics, India) of dimension $40 \mathrm{~mm} \times$ $40 \mathrm{~mm} \times 0.2 \mathrm{~mm}$ were used for the deposition of vanadium oxide thin films. Prior to the casting of thin films the substrates were cleaned sequentially for $5 \mathrm{~min}$ each with ethanol and deionised water. The synthesized gel was then spin coated over the dried substrates at various rpm (e.g., 1000, 2000, 3000 and 4000) for $30 \mathrm{~s}$. A semi-automatic spin coater (Model No: 121014, Delta Scientific Equipment Pvt. Ltd., Kolkata, India) was utilized for this purpose. The thin films were subsequently annealed with a heating rate of $3{ }^{\circ} \mathrm{C} \mathrm{min}{ }^{-1}$ for $1 \mathrm{~h}$ each in a vacuum furnace $\left(1.5 \times 10^{-5} \mathrm{mbar}\right.$, Hind High Vacuum, India) at different temperatures of 350,450 , and $550{ }^{\circ} \mathrm{C}$. The appearance of as- 

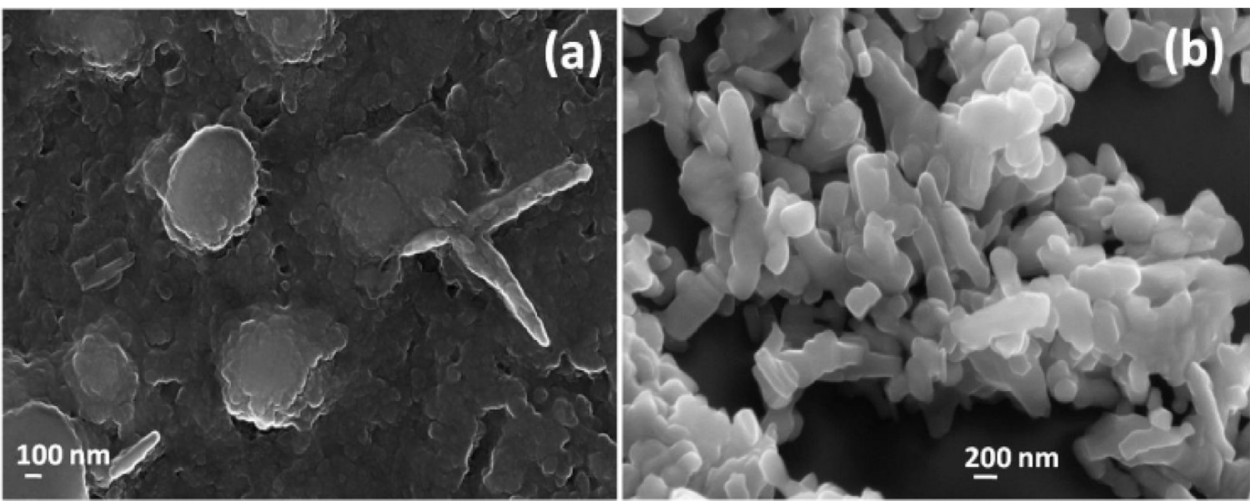

Fig. 2. FESEM images of vanadium oxide powders: (a) as-precipitated and (b) heat-treated at $450{ }^{\circ} \mathrm{C}$ in air.
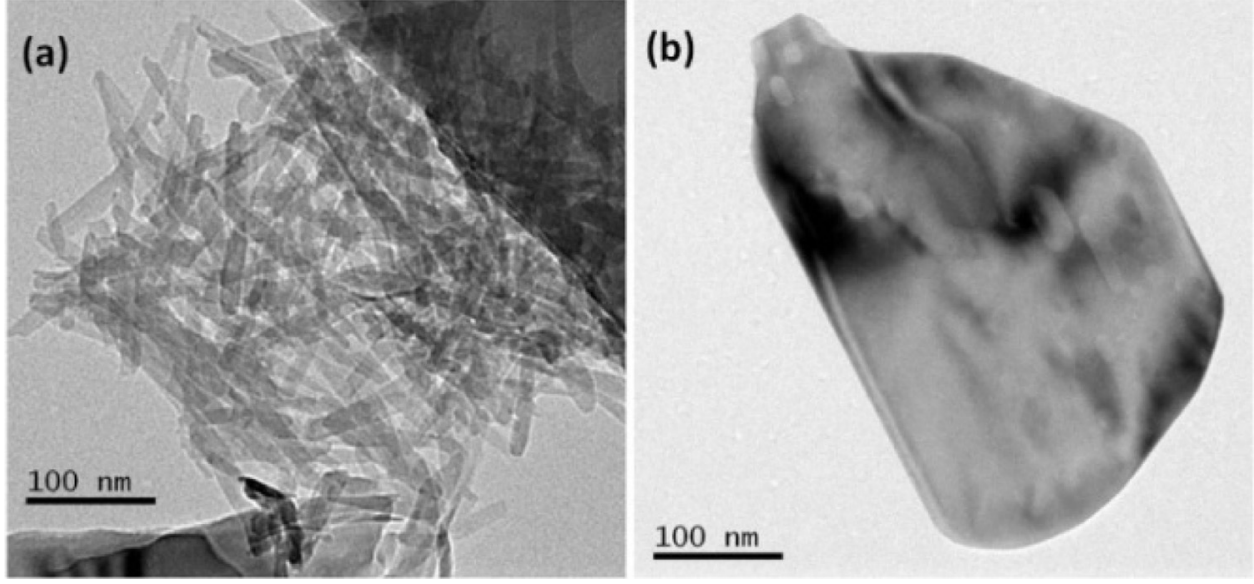

Fig. 3. TEM images of vanadium oxide powders: (a) as-precipitated and (b) heat-treated at $450{ }^{\circ} \mathrm{C}$ in air.


Fig. 4. XRD patterns of vanadium oxide thin films deposited at different rpm: (a) as-deposited and (b) annealed at $350{ }^{\circ} \mathrm{C}$ in vacuum.

grown film was yellow while the annealed film became bluish-black.

\subsection{Phase analysis of powders and thin films}

The phase analyses of the as-precipitated powder and post heat treated powder along with as-deposited and vacuum-annealed thin films were carried out by an X-ray diffractometer (X'pert Pro MPD, PANalytical, The Netherlands, Cu Ka1, $\lambda \sim 1.5414 \AA$, $40 \mathrm{kV}, 35 \mathrm{~mA}, 5^{\circ}$ $\leq 2 \theta \leq 80^{\circ}$ ). The $2 \theta$ step and data acquisition rates were kept at e.g., $0.05^{\circ} \mathrm{min}^{-1}$ and $0.5^{\circ} \mathrm{min}^{-1}$, respectively. The phase purities of the vanadium oxide powders and film were analyzed by the corresponding ICSD files.

\subsection{Microstructural studies of powders and thin films}

The microstructural characterizations of the as-precipitated and post heat-treated powder along with as-deposited and vacuum annealed thin films were carried out by FESEM (Supra VP35, Carl Zeiss, Germany). To avoid charging a thin (e.g., 50-70 ̊) film of carbon/gold was deposited on the samples prior to insertion in the FESEM chamber. 

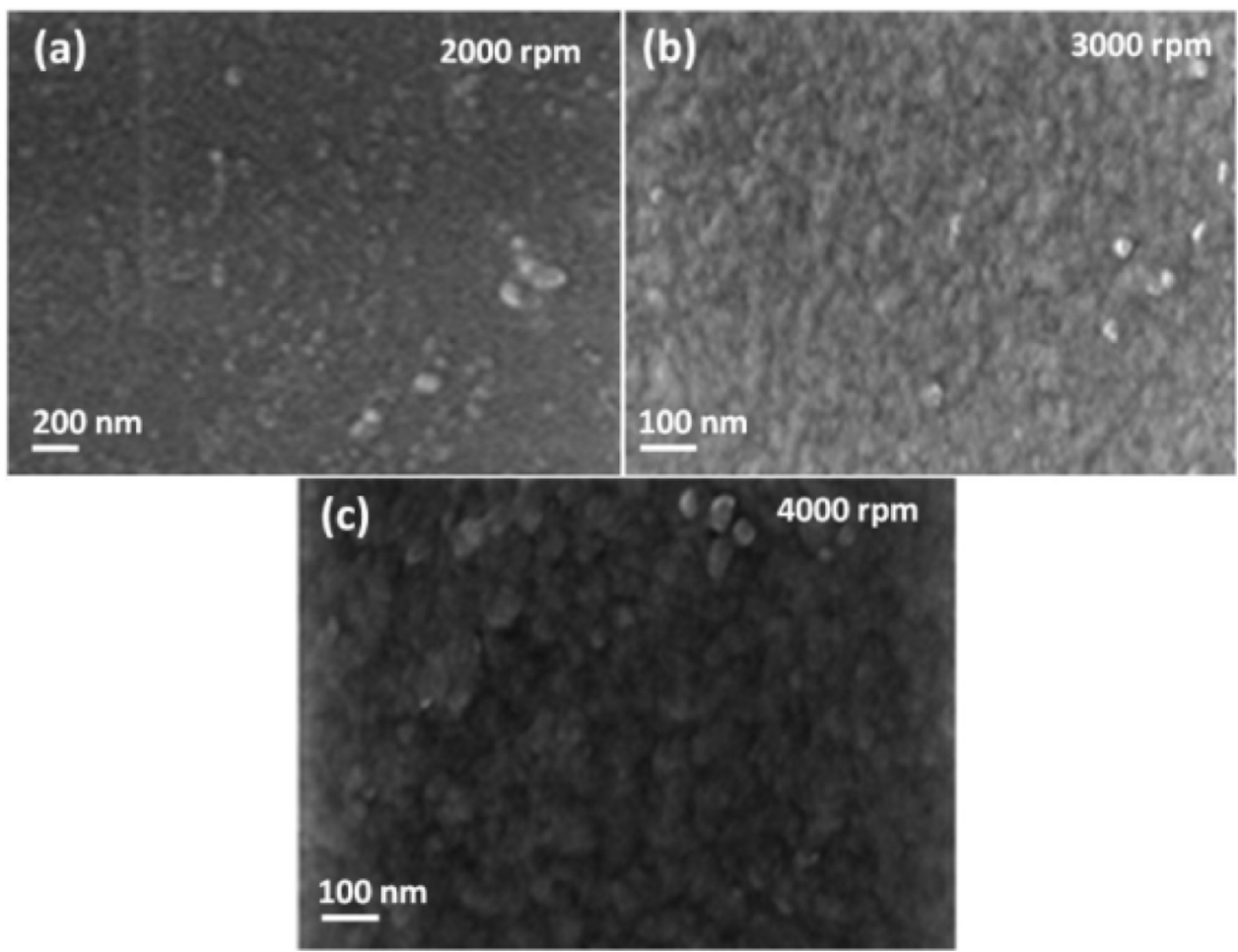

Fig. 5. FESEM images of vanadium oxide thin films deposited at: (a) 2000, (b) 3000 and (4) $4000 \mathrm{rpm}$.

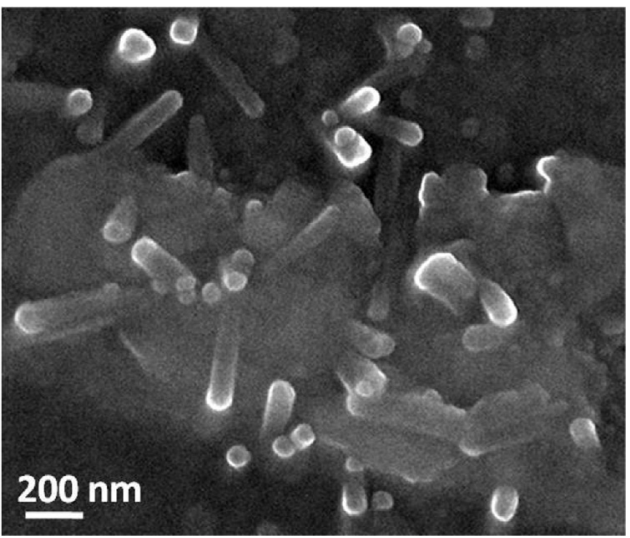

Fig. 6. Typical FESEM image of vanadium oxide thin films deposited at $3000 \mathrm{rpm}$ and subsequently annealed at $350^{\circ} \mathrm{C}$ in vacuum.

Further, microstructural characterizations of the as-precipitated and heat-treated powders were also carried out by TEM (Tecnai G2 30, STwin, $300 \mathrm{kV}$, FEI, The Netherlands). The thickness of the optimized film grown by spin coating at $3000 \mathrm{rpm}$ was measured by the noncontact mode surface profilometry technique (3400E, Bruker, USA).

\subsection{XPS study of thin films}

XPS of as-deposited and annealed films were recorded with a SPECS spectrometer using $\mathrm{X}$-ray source of non-monochromatic $\mathrm{Al} \mathrm{K \alpha}$ radiation $(1486.6 \mathrm{eV})$ operated at $150 \mathrm{~W}(12 \mathrm{kV}, 12.5 \mathrm{~mA})$. Survey spectra was obtained with pass energy of $70 \mathrm{eV}$ with step increment of $0.5 \mathrm{eV}$, whereas individual spectra were recorded with pass energy and step increment of 25 and $0.05 \mathrm{eV}$, respectively. V2p and $\mathrm{O} 1 \mathrm{~s}$ core level spectra were curve-fitted with Gaussian-Lorentzian peaks after Shirley background subtraction employing the Casa XPS program.

\subsection{Thermo-optical and electrical characterizations of thin films}

The average solar transmittance, reflectance and absorptance were evaluated by the solar spectrum reflectometer (SSR) both in reflectance and transmittance mode (SSR-E, Devices and Services Co., USA) as per ASTM C1549-09. Further, the average IR emittance of the deposited films on quartz was measured by an emissometer (AE, Devices and Services Co., USA) using the standard ASTM C1371-04a. Average sheet resistances of the films were examined by a portable two point resistance probe meter (e.g., Model 152-1, Trek Inc., USA).

\subsection{Nanomechanical characterizations of thin films}

The nanomechanical properties e.g., nanohardness $(\mathrm{H})$ and Young's modulus (E) of the optimized films were evaluated by the nanoindentation (TriboIndenter Ubi 700, Hysitron Inc., Minneapolis, MN, USA) technique at six different loads (i.e., from 100 to $1000 \mu \mathrm{N}$ ) utilizing a Berkovich diamond indenter. The load and depth resolutions of the nanoindenter were $1 \mathrm{nN}$ and $0.04 \mathrm{~nm}$, respectively. The thermal drift was kept at less than $0.05 \mathrm{~nm} \mathrm{~s}^{-1}$.

\subsection{Studies of phase transition of thin films}

The DSC (Q100, TA Instruments, USA) technique was used to study the phase transition temperature of the vacuum annealed vanadium oxide films. For this purpose, the experiments were conducted in a helium environment. Also, in all the DSC experiments the heating rate was kept constant as $10^{\circ} \mathrm{C} \mathrm{min}^{-1}$.

\section{Results and discussion}

\subsection{Characterization of powders}

\subsubsection{X-ray diffraction analysis of powders}

The XRD patterns of as-precipitated heat-treated powder are shown in Fig. 1(a-b), respectively. The XRD data of the as-precipitated powder 


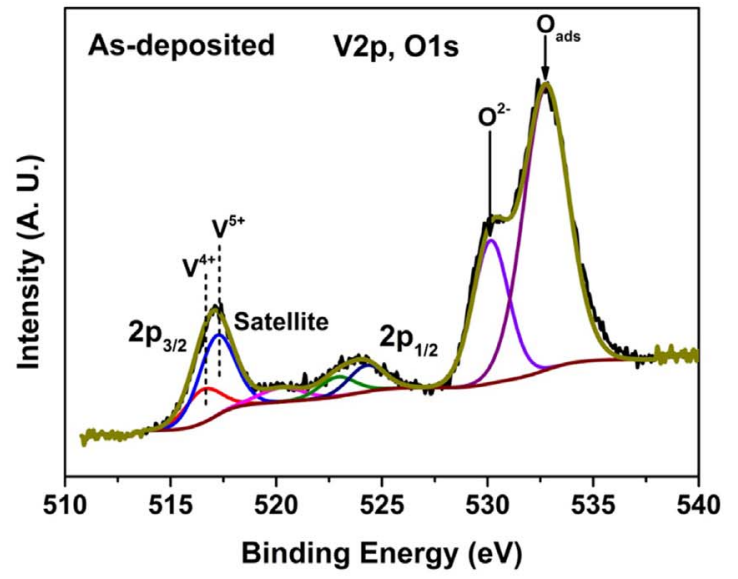

(a)

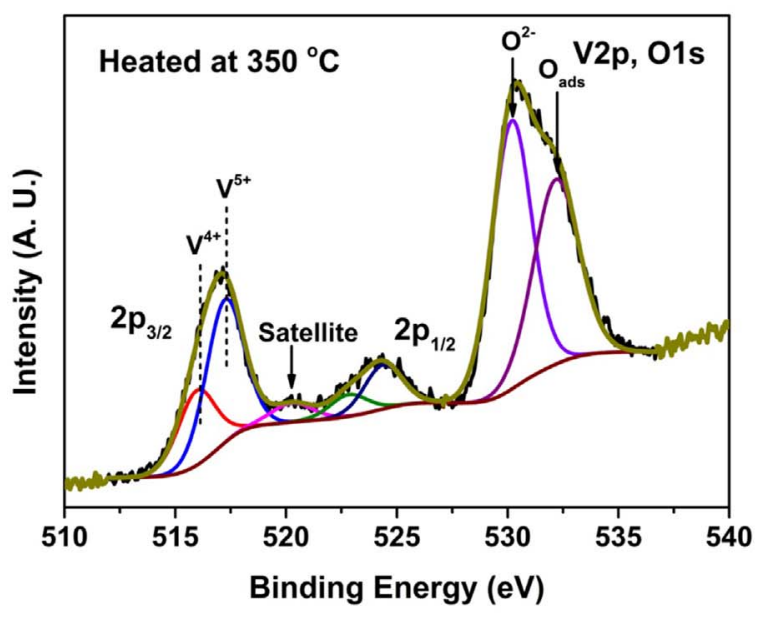

(b)

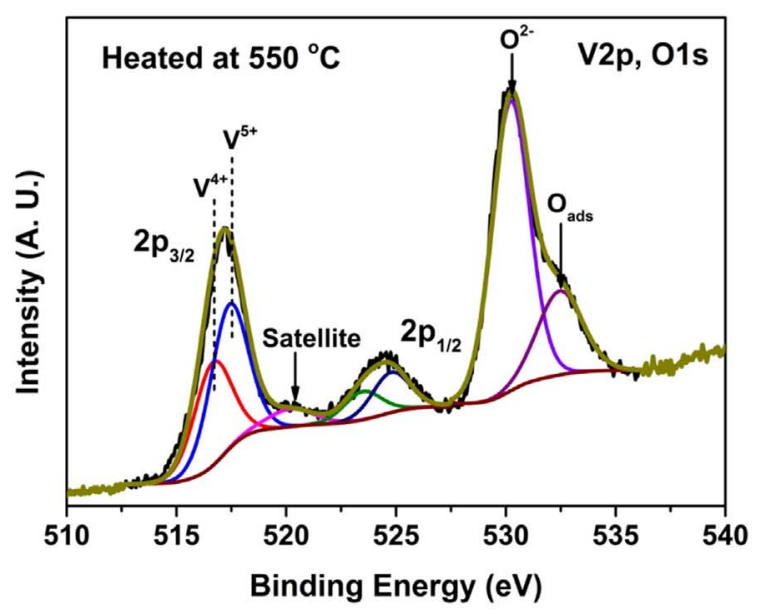

(c)

Fig. 7. Curve-fitted V2p and O1s core level spectra of (a) as-deposited and vacuum-annealed vanadium oxide thin films at (b) $350^{\circ} \mathrm{C}$ and (c) $550^{\circ} \mathrm{C}$.

(Fig. 1a) was not very highly crystalline while those (Fig. 1b) of the powder heat-treated at $450{ }^{\circ} \mathrm{C}$ showed highly crystalline nature. According to the standard data (ICSD colection code- 15984) the powder was indexed as phase pure orthorhombic $\mathrm{V}_{2} \mathrm{O}_{5}$ (Fig. 1b). The major peaks located in Fig. $1 \mathrm{~b}$ at around $2 \theta$ values of e.g., $\sim 15.35^{\circ}, 20.26^{\circ}$, $21.69^{\circ}, 26.12^{\circ}, 31.01^{\circ}, 32.34^{\circ}$ and $34.29^{\circ}$ indicated the presence of the
Table 1

Binding energies and relative peak areas of $\mathrm{V}$ species as obtained from V2p core level spectra of as-deposited and heat-treated $\mathrm{V}_{2} \mathrm{O}_{5}$ films deposited by spin coating.

\begin{tabular}{llll}
\hline Films & V species & $\begin{array}{l}\text { Binding energy of } \\
\text { V2p }_{\mathbf{3} / 2}(\mathrm{eV})\end{array}$ & $\begin{array}{l}\text { Relative peak area } \\
(\%)\end{array}$ \\
\hline As-deposited & $\mathrm{V}^{4+}$ & 516.4 & 29 \\
& $\mathrm{~V}^{5+}$ & 517.2 & 71 \\
\multirow{2}{*}{ Annealed at $350^{\circ} \mathrm{C}$} & $\mathrm{V}^{4+}$ & 516.1 & 34 \\
& $\mathrm{~V}^{5+}$ & 517.2 & 66 \\
Annealed at $550^{\circ} \mathrm{C}$ & $\mathrm{V}^{4+}$ & 516.5 & 42 \\
& $\mathrm{~V}^{5+}$ & 517.3 & 58 \\
\end{tabular}

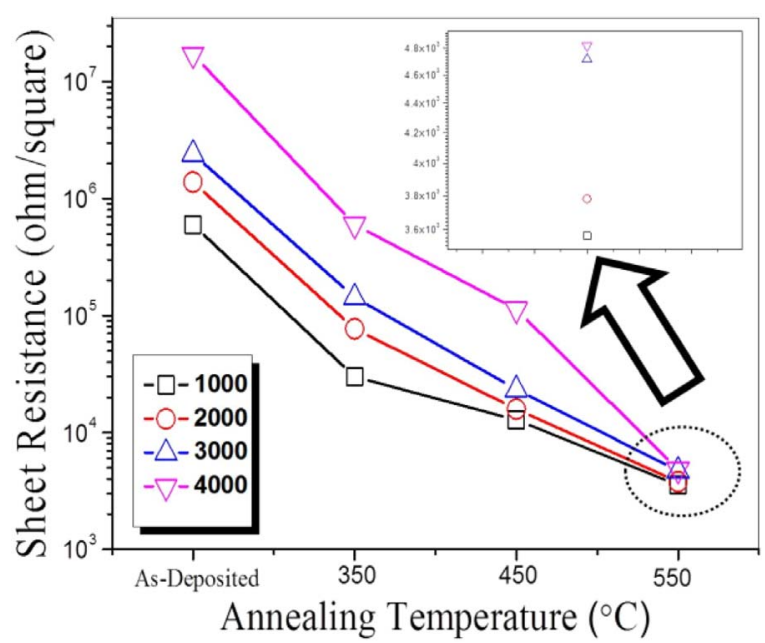

Fig. 8. Effect of vacuum annealing temperatures on sheet resistance of the vanadium oxide thin films deposited at 1000, 2000, 3000 and $4000 \mathrm{rpm}$.

(200), (001), (101), (110), (400), (011), and (301) planes with the corresponding inter-planar spacing of e.g., $\sim 5.76,4.37,4.09,3.40$, $2.87,2.76$, and $2.61 \AA$, respectively. The minor peaks were also identified meticulously. The data along with lattice constants e.g., $a=11.56 \AA, b=3.5 \AA$ and $c=4.38 \AA$ matched well with the standard powder diffraction data (ICSD collection code- 15984).

\subsubsection{Electron microscopy studies of powders}

Fig. 2a represents the typical FESEM micrograph of the as-precipitated powder. The micrograph of Fig. 2a reveals typical self-assembled agglomerated stacks of nano-rod like structures. This agglomeration possibly took place due to presence of adsorbed water molecules. Those nano-rods have a tendency to self-assemble further and to stack up in a stochastic fashion in a layer by layer architecture to form nano-rods of higher dimension upon heat treatment at higher temperature. Fig. 2b represents surface morphological FESEM micrograph of the $\mathrm{V}_{2} \mathrm{O}_{5}$ powder heat-treated at $450{ }^{\circ} \mathrm{C}$. It appears to indicate regular stacking and unidirectional growth leading to the formation of almost trapezoidal shaped particles.

A typical illustrative bright field TEM image of the as-precipitated powder is shown in Fig. 3a. The micrograph reveals rod like structures with typical average length of $\sim 88 \mathrm{~nm}$ and diameter of $\sim 10-20 \mathrm{~nm}$. However, nano-rods of even smaller and higher lengths were also present in the assembly. Similarly, a typical illustrative bright field image of $\mathrm{V}_{2} \mathrm{O}_{5}$ powder heat-treated at $450{ }^{\circ} \mathrm{C}$ is shown in Fig. $3 \mathrm{~b}$. The micrograph reveals the presence of stacked $\mathrm{V}_{2} \mathrm{O}_{5}$ nano-rods with typical average length of $\sim 240 \mathrm{~nm}$ and diameter of $\sim 140-200 \mathrm{~nm}$. The heat treatment allowed growth as well as side by side stacking of nano-rods to generate agglomerated rods of higher dimensions which exactly corroborates with the FESEM images discussed earlier in this study (Fig. 2a-b). 

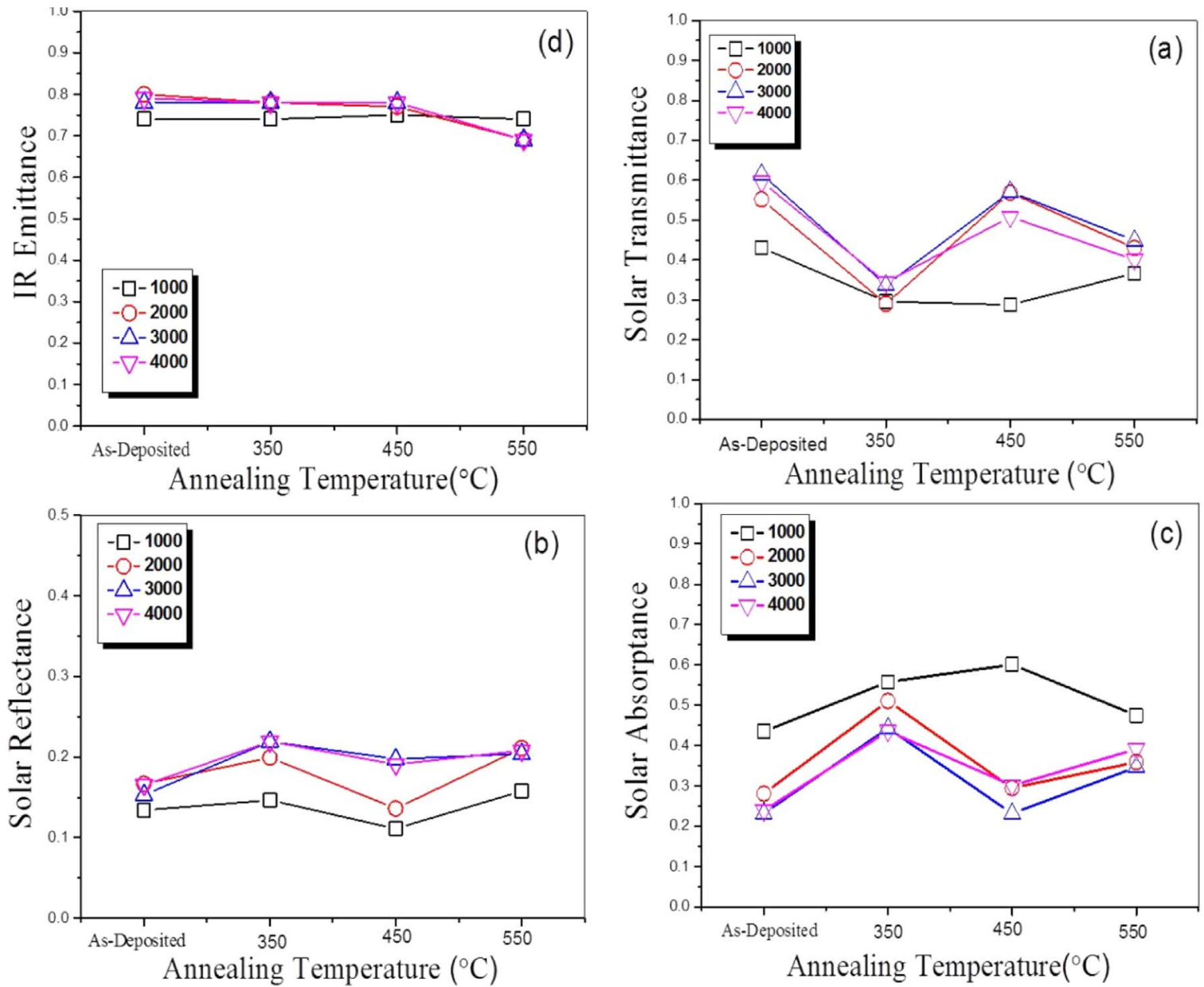

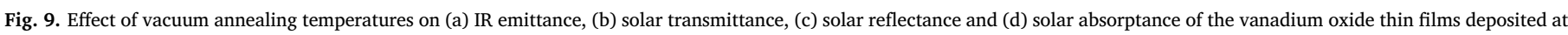
$1000,2000,3000$ and $4000 \mathrm{rpm}$.

\subsection{Characterization of the films}

\subsubsection{X-ray diffraction analysis of the films}

Fig. 4a represents the XRD patterns recorded for as-deposited thin films deposited on quartz substrates at various rpm viz., 1000, 2000, 3000 and 4000. The as-deposited thin films showed the presence of crystalline $\mathrm{V}_{2} \mathrm{O}_{5}, \mathrm{nH}_{2} \mathrm{O}$ xerogel system revealing maximum intensity peak along (001) plane that matched well with standard data (ICSD collection code- 94905). Further, the XRD patterns of thin films subsequently vacuum-annealed at $350{ }^{\circ} \mathrm{C}$ are shown in Fig. $4 \mathrm{~b}$. The vacuum-annealed thin films deposited at various rpm showed the presence of $\mathrm{VO}_{2}$ (ICSD collection code- 73855). Similar observations were also found for film which had undergone vacuum heat treatments at other temperatures. Thus, the presence of the $\mathrm{VO}_{2}$ was expected because other researchers $[33,35,36]$ also had reported similar observations after annealing in vacuum.

\subsubsection{FESEM studies of the thin films}

Fig. 5(a-c) represents the typical FESEM micrographs of the as-deposited thin films grown on quartz substrates at different rpm e.g., 2000, 3000 and 4000, respectively. The surface microstructure reveals smooth, uniform, dense and grainy structures covering the entire surfaces of the corresponding quartz substrates.

Fig. 6 represents a typical microstructure of the film vacuum annealed at $350{ }^{\circ} \mathrm{C}$. The pronounced growth of nano-rod is observed (Fig. 6). When the films are annealed at vacuum, the heat provided to the substrate supplied activation energy to the granular particles. The activation energy, in turn, helped the granular particles to initiate preferred directional growth leading to the formation of nano-rods with length of about $300-400 \mathrm{~nm}$ and diameter of about $65 \mathrm{~nm}$.

\subsubsection{XPS studies of the thin films}

The typical illustrative V2p and O1s core level spectra of as-deposited, a low temperature (e.g., $350{ }^{\circ} \mathrm{C}$ ) vacuum-annealed and a high temperature (e.g., $550{ }^{\circ} \mathrm{C}$ ) vacuum-annealed films are shown in Fig. 7(ac), respectively. Further, binding energies and relative peak areas of vanadium species as obtained from V2p core level spectra of as-deposited and heat-treated vanadium oxide films are summarized in Table 1. It is interesting to note that both as-deposited and vacuumannealed films show the presence of only $\mathrm{V}^{5+}$ and $\mathrm{V}^{4+}$ species. The other phases of such as $\mathrm{V}^{2+}$ and $\mathrm{V}^{3+}$ are not present here which are often found in literature for the films developed by sputtering based techniques $[10,11]$. Further, the post annealing treatment in vacuum shows increase in $\mathrm{V}^{4+}$ species as expected. This observation was also well corroborated with the corresponding XRD data discussed in Section 3.2.1. It is therefore conjectured that during vacuum annealing process loosely bound oxygen atoms at the surface of the xerogel thin films were basically coming out of the $\mathrm{V}_{2} \mathrm{O}_{5}$ moiety thereby undergoing a reduction which, in turn, had resulted in a decrease in the state of oxidation from $\mathrm{V}^{5+}$ to $\mathrm{V}^{4+}$, Fig. 7(a-c).

\subsubsection{Sheet resistance of the thin films}

The $R_{s}$ values of the films deposited at different rpm viz., 1000, 2000, 3000, and 4000 are shown in Fig. 8 as a function of the post annealing heat treatment temperatures in vacuum. The data provided in Fig. 8 confirmed that for any given temperature of vacuum annealing 


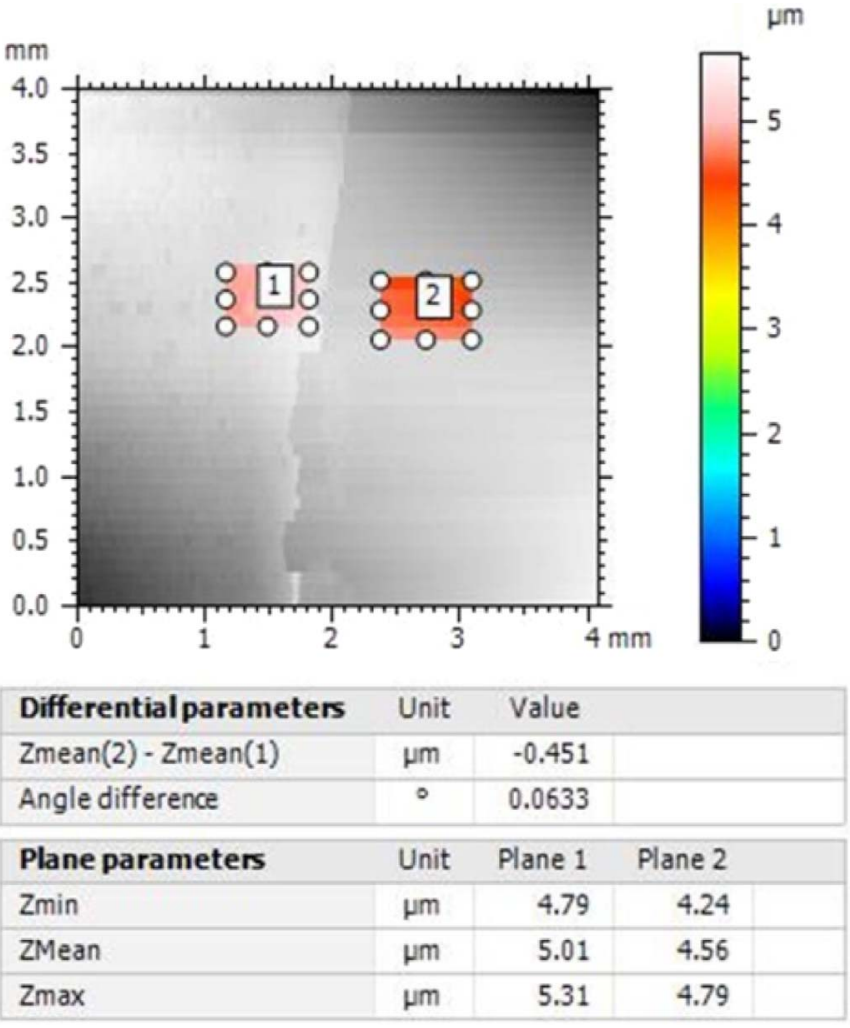

Fig. 10. Thickness of a typical vanadium oxide thin film deposited at optimized process condition of $3000 \mathrm{rpm}$.

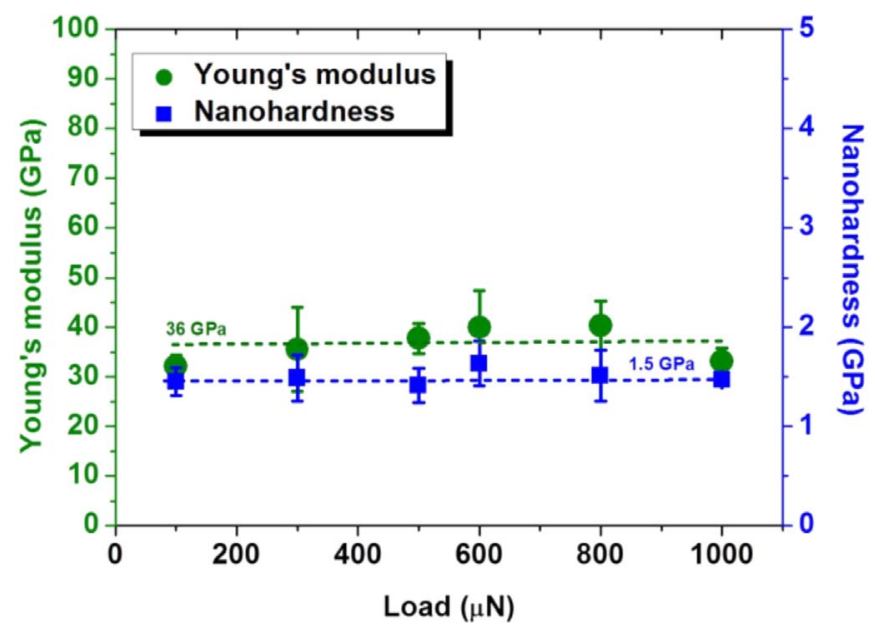

Fig. 11. Plot of nanohardness and Young's modulus as a function of load for a typical vanadium oxide thin film deposited at an optimized process condition of $3000 \mathrm{rpm}$.

as well as for as-deposited condition, the $R_{s}$ value of the vanadium oxide thin films were increased with increase in rpm from 1000 to 4000. On the other hand, $R_{s}$ was decreased with increase in post annealing temperature because of increase in $\mathrm{V}^{4+}$ species which corroborated well with the data (Table 1) obtained from the XPS investigation, as discussed above. Thus, the significant reduction in oxidation state of vanadium from $\mathrm{V}^{5+}$ to $\mathrm{V}^{4+}$ in post annealing condition gave rise to enhancement in carrier density or oxygen vacancies in the films which had, in turn, decreased the sheet resistance of the annealed films $[33,37,38]$.

\subsubsection{Thermo-optical properties of thin films}

IR emittance and optical properties such as solar transmittance, reflectance and absorptance of the spin-coated thin films grown at different rpm are shown as a function of vacuum annealing temperature in Fig. 9(a-d), respectively. The IR emittance of the coated films were almost similar to that (e.g., $\sim 0.8$ ) of the bare quartz. Further, no noteworthy alteration was observed while it measured either a low (glossy metallic surface) or high (black surface) emitting standard surfaces provided by the supplier. This observation supported the IR transparency behaviour of vanadium oxide [1] and it would become opaque beyond the phase transition temperature.

Further, the thin films showed $\sim 30-60 \%$ reduction in average transmittance, $\sim 10-16 \%$ increment in reflectance and $\sim 22-58 \%$ increment in absorptance with respect to the optical properties of bare quartz. The magnitude of solar transmittance was measured to be the highest e.g., 0.62 for the thin films deposited at $3000 \mathrm{rpm}$ and was the least e.g., 0.44 for the thin films deposited at $1000 \mathrm{rpm}$ Further, the variation in transmittance was not so systematic with respect to increase in post annealing heat treatment temperatures in vacuum.

The magnitudes of reflectance were nearly similar (e.g., around 0.15-0.16) for the films deposited at 3000 and $4000 \mathrm{rpm}$ and was the least e.g., 0.12 for the film deposited by spin coating at $1000 \mathrm{rpm}$ (Fig. 9c). The maximum reflectance data e.g., $\sim 0.22$ was measured after vacuum annealing at $350{ }^{\circ} \mathrm{C}$ for the films grown by spin coating at 3000 and $4000 \mathrm{rpm}$.

On the other hand, the lowest absorptance value e.g., 0.23 was measured for the as-deposited film grown by spin coating at $3000 \mathrm{rpm}$ (Fig. 9d). Further, akin to the case of transmittance; the variation in absorptance was not so systematic with respect to increase in post annealing heat treatment temperatures in vacuum. Therefore, on the basis of the lowest absorptance property with high transmittance value, the spin coating of thin films at $3000 \mathrm{rpm}$ was judiciously identified as the optimized processing condition which would be beneficial from spacecraft thermal control application point of view.

\subsubsection{Thickness and nanomechanical properties of the optimized films}

Fig. 10 represents a typical non-contact surface profilometry data of thickness of as-deposited thin films grown at $3000 \mathrm{rpm}$ which was identified above as the optimized processing condition. The average thickness value was evaluated as $\sim 450 \mathrm{~nm}$. To determine the structural integrity of this process optimized vanadium oxide thin film, the nanoindentation technique was utilized to evaluate the mechanical properties. The variations in $\mathrm{H}$ and $\mathrm{E}$ as a function of different loads (e.g., from 100 to $1000 \mu \mathrm{N}$ ) are shown in Fig. 11. Both the $\mathrm{H}$ and $\mathrm{E}$ values are found to be constant at $\sim 1.5 \mathrm{GPa}$ and $\sim 36 \mathrm{GPa}$, respectively. The $\mathrm{H}$ and $\mathrm{E}$ data of dip-coated vanadium oxide films [39] are reported to be $0.07 \mathrm{GPa}$ and $2.31 \mathrm{GPa}$, respectively while sputtered vanadium oxide film [1] show the $\mathrm{H}$ and $\mathrm{E}$ values of $\sim 0.2$ and $8.5 \mathrm{GPa}$, respectively. Thus, the data measured in the present study for the spincoated vanadium oxide thin films suggested the presence of nanomechanical properties which were distinctly higher than those reported in literature $[3,39]$. It is suggested that the superior nanomechanical properties of the present oxide films could be linked to the presence of high crystallinity (Fig. 4b) and nanostructured surface morphology (Fig. 5b), respectively. However, further dedicated study of this aspect, which is beyond the scope of the present work; should frame the scope of our future work in this arena.

\subsubsection{Phase transition properties of the thin films}

DSC curves of bare quartz, thin films grown at an optimized rpm (viz., $3000 \mathrm{rpm}$ ) and subsequently vacuum-annealed at 350, 450 and $550{ }^{\circ} \mathrm{C}$ are shown in Fig. 12(a-d), respectively. As expected, the bare quartz substrate did not exhibit any signature of phase transition during heating and cooling cycle (Fig. 12a). However, the most interesting and promising observation is that the vacuum-annealed films on quartz substrates showed the reversible phase transition in the temperature regime of $\sim 44-48{ }^{\circ} \mathrm{C}$. This phase transition was quite stable as beyond the transition temperature, no signatures of any phase transition was 



Fig. 12. DSC curves of (a) bare quartz and process optimized vanadium oxide thin films on quartz vacuum-annealed at (b) $350{ }^{\circ} \mathrm{C}$, (c) $450{ }^{\circ} \mathrm{C}$ and (d) $550{ }^{\circ} \mathrm{C}$.

identified as the temperature was allowed to continuously rise up to as high as e.g., $300{ }^{\circ} \mathrm{C}$ (plot not shown here), Fig. 12 (b-d). This observation further confirmed the stability of the present optimized condition processed films up to $300^{\circ} \mathrm{C}$.

In all the cases for each film, three heating and three cooling cycles had been deliberately carried out to examine the repeatability of the phase transition. The transition peaks appeared to be almost overlapped with each other, Fig. 12(b-d). This particular observation proved undoubtedly the repeatable and reversible phase transition behaviour of the process optimized thin films.

Further, it is observed from the experimental data (Fig. 12b-d) that in the heating cycles the phase transition peaks appeared at $\sim 48^{\circ} \mathrm{C}$ and it reduced only marginally to $\sim 44^{\circ} \mathrm{C}$ during cooling cycles. These data confirmed further that these films inherently had a low hysteresis loss.

Thus, in the present work, the lower transition temperature i.e., 44 to $\sim 48^{\circ} \mathrm{C}$ was measured (Fig. $12 \mathrm{~b}-\mathrm{d}$ ). This transition temperature was significantly lower than the transition temperature (i.e., $68^{\circ} \mathrm{C}$ ) of pure and bulk $\mathrm{VO}_{2}$. The lower transition temperature of the present spin-coated thin films on quartz substrates could be primarily linked with the size effect [11]. Due to size effect, the significant reduction of transition temperature e.g., $54^{\circ} \mathrm{C}[40]$ and $29^{\circ} \mathrm{C}[23,24]$ of pure single layer $\mathrm{VO}_{2}$ film were observed by Balakrishnan et al. [40], Wang et al. [23] and Hongwei et al. [24]. The introduction of interfacial and biaxial strain can also cause the decrease in transition temperature as reported by Kittiwatanakul et al. [20] and Fan et al. [21]. From the XRD data presented in Fig. 4b, it is observed that the intense characteristic peak of $\mathrm{VO}_{2}$ is appeared at around $38.84^{\circ}$ while ICSD standard pattern showed the same at $38.02^{\circ}$. Further, the lattice strain of the present $\mathrm{VO}_{2}$ film is calculated as 0.0195 as compared to the standard ICSD $\mathrm{VO}_{2}$ pattern. Thus, the strained lattice is also a contributing factor for the reduction of transition temperature observed in the present study. In another report by Viswanath et al. [41] showed a noteworthy decrease in phase transition temperature (up to $45^{\circ} \mathrm{C}$ ) of sandwiched $\mathrm{VO}_{2}$ film in between two $\mathrm{HfO}_{2}$ layers on the $\mathrm{Si}$ substrate due to geometrical confinement and the subsequent stress relaxation. However, in the present case, $\mathrm{VO}_{2}$ is deposited as single layer. Thus, it may be plausible to argue that the present low transition temperature of $\mathrm{VO}_{2}$ film may arise due to the combined effects of size and strained lattice.

The lower phase transition temperature of the present vanadium oxide films make their candidature very promising and most suitable for smart radiation device applications which could be utilized for spacecraft thermal control.

\section{Conclusions}

Phase pure, crystalline and nano-structured $\mathrm{V}_{2} \mathrm{O}_{5}$ powder was successfully synthesized using acid hydrolysis. Sol-gel spin coating technique was utilized to grow the vanadium oxide thin films on quartz and the deposited thin films were subsequently vacuum-annealed at different temperatures. Through XPS studies only $\mathrm{V}^{5+}$ and $\mathrm{V}^{4+}$ species were identified to be present in the current vanadium oxide films. On the basis of the lowest absorptance property with high transmittance value, the spin coating of thin films at $3000 \mathrm{rpm}$ was judiciously identified as the optimized processing condition which would be beneficial from spacecraft thermal control application point of view. Nanomechanical characterizations of the process optimized films revealed nanohardness of $\sim 1.5 \mathrm{GPa}$ and Young's modulus of $\sim 36 \mathrm{GPa}$ which were much higher than those reported for sol-gel based and 
sputtered vanadium oxide films. The temperature dependent phase transition characteristics of optimized vanadium oxide films were extensively studied. These results undoubtedly established that reproducible, reversible phase transition occurred in the range of $44-48^{\circ} \mathrm{C}$. This was linked to the formation of $\mathrm{VO}_{2}$ during post annealing in high vacuum. Finally, the reversible phase transition temperature of the process optimized thin films was much lower than the high phase transition temperature of $68^{\circ} \mathrm{C}$ usually reported for bulk $\mathrm{VO}_{2}$.

\section{Acknowledgements}

The authors (DM, MB and AKM) appreciate the kind supports and encouragements received from Dr. K Muraleedharan, Director, CSIRCGCRI, Kolkata during the course of the present work. These authors also acknowledge the supports received from AMMCD, MCID and AMCU of CSIR-CGCRI. The financial support of the Indian Space Research Organisation (ISRO) through the RESPOND Project (No. GAP 0245) is gratefully acknowledged. Further, we are grateful to Dr. H. C. Barshilia, Head, SED, CSIR-NAL for facilitating XPS tests under ISRO rate contract. We acknowledge the supports received from Mr. D. Raghavendra Kumar, ISAC/ISRO for the DSC measurement.

\section{References}

[1] K. Appavoo, D.Y. Lei, Y. Sonnefraud, B. Wang, S.T. Pantelides, S.A. Maier, R.F. Haglund, Role of defects in the phase transition of $\mathrm{VO}_{2}$ nanoparticles probed by plasmon resonance spectroscopy, Nano Lett. 12 (2012) 780-786.

[2] N.F. Mott, Metal-insulator transition, Rev. Mod. Phys. 40 (1968) 677-683.

[3] D. Porwal, A.C.M. Esther, I.N. Reddy, N. Sridhara, N.P. Yadav, D. Rangappa, P. Bera, C. Anandan, A.K. Sharma, A. Dey, Study of the structural, thermal, optical, electrical and nanomechanical properties of sputtered vanadium oxide smart thin films, RSC Adv. 5 (2015) 35737-35745.

[4] M. Kang, I. Kim, S.W. Kim, J.W. Ryu, H.Y. Park, Metal-insulator transition without structural phase transition in $\mathrm{V}_{2} \mathrm{O}_{5}$ film, Appl. Phys. Lett. 98 (2011) 131907.

[5] R.P. Blum, H. Niehus, C. Hucho, R. Fortrie, M.V. Ganduglia-Pirovano, J. Sauer, S. Shaikhutdinov, H.J. Freund, Surface metal-insulator transition on a vanadium pentoxide (001) single crystal, Phys. Rev. Lett. 99 (2007) 226103.

[6] A.S. Etman, H.D. Asfaw, N. Yuan, J. Lid, Z. Zhoud, F. Penga, I. Perssonc, X. Zoua, T. Gustafsson, K. Edströmand, J. Suna, One-step water based strategy for synthesizing hydrated vanadium pentoxide nanosheets from $\mathrm{VO}_{2}(\mathrm{~B})$ as free-standing electrodes for lithium battery applications, J. Mater. Chem. A 4 (2016) (17988 1800).

[7] H. Jerominek, F. Picard, D. Vincent, Vanadium oxide films for optical switching and detection, Opt. Eng. 32 (1993) 2092-2099.

[8] H. Zhou, J. Li, S. Bao, D. Wang, X. Liu, P. Jin, The potential cytotoxicity and me chanism of $\mathrm{VO}_{2}$ thin films for intelligent thermochromic windows, RSC Adv. 5 (2015) 106315-106324.

[9] S. Jin, B.J. Jung, C.K. Song, J. Kwak, Room-temperature and solution-processed vanadium oxide buffer layer for efficient charge injection in bottom-contact organic field-effect transistors, Curr. Appl. Phys. 14 (2014) 1809-1812.

[10] A. Dey, M.K. Nayak, A.C.M. Esther, M.S.P. Kumar, D. Porwal, A.K. Gupta, P. Bera, H.C. Barshilia, A.K. Mukhopadhyay, A.K. Pandey, K. Khan, M. Bhattacharya, D.R. Kumar, N. Sridhara, A.K. Sharma, Nanocolumnar crystalline vanadium oxidemolybdenum oxide antireflective smart thin films with superior nanomechanical properties, Sci. Rep. 6 (2016) 36811.

[11] D. Palai, A.C.M. Esther, D. Porwal, M.S. Pradeepkumar, D.R. Kumar, P. Bera, N. Sridharaand, A. Dey, Reversible phase transition in vanadium oxide films sputtered on metal substrates, Philos. Mag. Lett. 96 (2016) 440-446.

[12] M. Benkahoul, M. Chaker, J. Margot, E. Haddad, R. Kruzelecky, B. Wong, W. Jamroz, P. Poinas, Thermochromic $\mathrm{VO}_{2}$ film deposited on $\mathrm{Al}$ with tunable thermal emissivity for space applications, Sol. Energy Mater. Sol. Cells 95 (2011) 3504-3508.

[13] H.Y. Xu, Y.H. Huang, S. Liu, K.W. Xu, F. Ma, P.K. Chu, Effects of annealing ambient on oxygen vacancies and phase transition temperature of $\mathrm{VO}_{2}$ thin films, RSC Adv. 6 (2016) 79383-79388.

[14] M.A. Ashrafi, M. Ranjbar, H. Kalhori, H. Salamati, Pulsed laser deposition of Mo-VO thin films for chromogenic applications, Thin Solid Films 621 (2016) 220-228.

[15] A.M. Makarevich, I.I. Sadykov, D.I. Sharovarov, V.A. Amelichev, A.A. Adamenkov, D.M. Tsymbarenko, A.V. Plokhih, M.N. Esaulkov, P.M. Solyankine, A.R. Kaula, Chemical synthesis of high quality epitaxial vanadium dioxide films with sharp electrical and optical switch properties, J. Mater. Chem. C 3 (2015) 9197-9205.

[16] O. Berezina, D. Kirienko, A. Pergament, G. Stefanovich, A. Velichko, V. Zlomanov,
Vanadium oxide thin films and fibers obtained by acetylacetonate sol-gel method, Thin Solid Films 574 (2014) 15-19.

[17] M. Hajzeri, A. Vuk, L.S. Perse, M. Colovic, B. Herbig, U. Posset, M. Krzmanc, B. Orel, Sol-gel vanadium oxide thin films for a flexible electronically conductive polymeric substrate, Sol. Energy Mater. Sol. Cells 99 (2012) 62-72.

[18] Y. Li, S. Ji, Y. Gao, H. Luoand, M. Kanehira, Core-shell VO $\mathrm{VO}_{2} @ \mathrm{TiO}_{2}$ nanorods that combine thermochromic and photocatalytic properties for application as energysaving smart coatings, Sci. Rep. 3 (2013) 1370.

[19] M. Yang, Y. Yang, B. Hong, L. Wang, K. Hu, Y. Dong, H. Xu, H. Huang, J. Zhao, H. Chen, L. Song, H. Ju, J. Zhu, J. Bao, X. Li, Y. Gu, T. Yang, X. Gao, Z. Luoand, C. Gao, Suppression of structural phase transition in $\mathrm{VO}_{2}$ by epitaxial strain in vicinity of metal-insulator transition, Sci. Rep. 6 (2016) 23119.

[20] S. Kittiwatanakul, S.A. Wolf, J. Lu, Large epitaxial bi-axial strain induces a mott-like phase transition in $\mathrm{VO}_{2}$, Appl. Phys. Lett. 105 (2014) 073112.

[21] L.L. Fan, S. Chen, Z.L. Luo, Q.H. Liu, Y.F. Wu, L. Song, D.X. Ji, P. Wang, W.S. Chu, C. Gao, C.W. Zou, Z.Y. Wu, Strain dynamics of ultrathin $\mathrm{VO}_{2}$ film grown on $\mathrm{TiO}_{2}$ (001) and the associated phase transition modulation, Nano Lett. 14 (2014) 4036-4043.

[22] Y. Qiao, J. Chen, Y. Lu, X. Yang, H. Yang, K. Xu, Fabrication of low phase transition temperature vanadium oxide films by direct current reactive magnetron sputtering and oxidation post-anneal method, Infrared Phys. Technol. 67 (2014) 126-130.

[23] B. Wang, S. Chen, Z. Huang, M. Fu, Optical nonlinearities of nanostructured $\mathrm{VO}_{2}$ thin films with low phase transition temperature, Appl. Surf. Sci. 258 (2012) 5319-5322.

[24] L. Hongwei, L. Junpeng, Z. Minrui, T.S. Hai, S.C. Haur, Z. Xinhai, K. Lin, Size effects on metal-insulator phase transition in individual vanadium dioxide nanowires, Opt Express 22 (2014) 30748-30755.

[25] S. Lu, L. Hou, F. Gan, Surface analysis and phase transition of gel-derived $\mathrm{VO}_{2}$ thin films, Thin Solid Films 353 (1999) 40-44.

[26] N. Wang, G.Q. Sheng, L.P. Lin, S. Magdassi, Y. Long, One-step hydrothermal synthesis of rare earth/W-codoped $\mathrm{VO}_{2}$ nanoparticles: reduced phase transition temperature and improved thermochromic properties, J. Alloy. Compd. 711 (2017) $222-228$.

[27] M. Wan, M. Xiong, N. Li, B. Liu, S. Wang, W.Y. Ching, X. Zhao, Observation of reduced phase transition temperature in $\mathrm{N}$-doped thermochromic film of monoclinic $\mathrm{VO}_{2}$, Appl. Surf. Sci. 410 (2017) 363-372.

[28] G.R. Khan, K. Asokan, B. Ahmad, Room temperature tunability of Mo-doped VO nanofilms across semiconductor to metal phase transition, Thin Solid Films 625 (2017) 155-162.

[29] Y. Lu, L. Liu, D. Mandler, P.S. Lee, High switching speed and coloration efficiency of titanium-doped vanadium oxide thin film electrochromic devices, J. Mater. Chem. C 1 (2013) 7380-7386.

[30] N. Wang, S. Liu, X.T. Zeng, S. Magdassiand, Y. Long, Mg/W-codoped vanadium dioxide thin films with enhanced visible transmittance and low phase transition temperature, J. Mater. Chem. C 3 (2015) 6771-6777.

[31] D. Li, M. Li, J. Pan, Y. Luo, H. Wu, Y. Zhang, L. Guanghai, Hydrothermal Synthesis of Mo-Doped $\mathrm{VO}_{2} / \mathrm{TiO}_{2}$ Composite nanocrystals with enhanced thermochromic performance, ACS Appl. Mater. Interfaces 6 (2014) 6555-6561.

[32] A. Jin, W. Chem, Q. Zhub, Z. Jian, Multi-electrochromism behavior and electrochromic mechanism of electrodeposited molybdenum doped vanadium pentoxide films, Electrochim. Acta 55 (2010) 6408-6414.

[33] D. Porwal, A.C.M. Esther, A. Dey, A.K. Gupta, D.R. Kumar, P. Bera, H.C. Barshilia, M. Bhattacharya, A.K. Mukhopadhyay, K. Khan, A.K. Sharma, Effect of low temperature vacuum annealing on microstructural, optical, electronic, electrical, nanomechanical properties and phase transition behavior of sputtered vanadium oxide thin films, Mater. Res. Express 3 (2016) 106407.

[34] G. Rampelberg, B. Schutter, W. Devulder, K. Martens, I. Radu, C. Detaverniera, In situ X-ray diffraction study of the controlled oxidation and reduction in the $\mathrm{V}-\mathrm{O}$ system for the synthesis of $\mathrm{VO}_{2}$ and $\mathrm{V}_{2} \mathrm{O}_{3}$ thin films, J. Mater. Chem. C 3 (2015) 11357-11365.

[35] M. Benmoussa, E. Ibnouelghazi, A. Bennouna, E.L. Ameziane, Structural, electrical and optical properties of sputtered vanadium pentoxide thin films, Thin Solid Films 265 (1995) 22-28.

[36] D.Q. Liu, W.W. Zheng, H.F. Cheng, H.T. Liu, Thermochromic $\mathrm{VO}_{2}$ thin film prepared by post annealing treatment of $\mathrm{V}_{2} \mathrm{O}_{5}$ thin film, Adv. Mater. Res. 79 (2009) 747-750.

[37] R.M. Oksuzoglu, P. Bilgiç, M. Yildirim, O. Deniz, Influence of post-annealing on electrical, structural and optical properties of vanadium oxide thin films, Opt. Laser Technol. 48 (2013) 102-109.

[38] H.Y. Xu, Y.H. Huang, S. Liu, K.W. Xu, F. Ma, P.K. Chu, Effects of annealing ambient on oxygen vacancies and phase transition temperature of $\mathrm{VO}_{2}$ thin films, RSC Adv. 6 (2016) 79383-79388.

[39] B. Bera, P.S. Das, M. Bhattacharya, S. Ghosh, A.K. Mukhopadhyay, A. Dey, Nanoscale contact resistance of $\mathrm{V}_{2} \mathrm{O}_{5}$ xerogel films developed by nanostructured powder, J. Phys. D: Appl. Phys. 49 (2016) 085303.

[40] V. Balakrishnan, C. Ko, S. Ramanathan, Size effects on stress relaxation across the metal-insulator transition in $\mathrm{VO}_{2}$ thin films, J. Mater. Res. 26 (2011) 1384-1387.

[41] V. Balakrishnan, C. Ko, Z. Yang, S. Ramanathan, Geometric confinement effects on the metal-insulator transition temperature and stress relaxation in $\mathrm{VO}_{2}$ thin films grown on silicon, J. Appl. Phys. 109 (2011) 063512. 